\title{
Prognostic factors for melanoma brain metastases treated with stereotactic radiosurgery
}

\author{
Shelly X. Bian, MD, ${ }^{1}$ David Routman, MD, ${ }^{1}$ Jonathan Liu, MD, ${ }^{1}$ Dongyun Yang, PhD, ${ }^{4}$ \\ Susan Groshen, PhD, ${ }^{4}$ Gabriel Zada, MD, ${ }^{2}$ Nicholas Trakul, MD, PhD, ${ }^{1}$ Michael K. Wong, MD, ${ }^{3}$ \\ Cheng Yu, PhD, ${ }^{1}$ and Eric L. Chang, MD' \\ Departments of ${ }^{1}$ Radiation Oncology, ${ }^{2}$ Neurosurgery, ${ }^{3}$ Medical Oncology, and ${ }^{4}$ Biostatistics, University of Southern California, \\ Keck School of Medicine, Los Angeles, California
}

OBJECTIVE Stereotactic radiosurgery (SRS) is routinely used to treat brain metastases from melanoma due to their radioresistant nature. The median survival for these patients is 4-6 months, according to earlier studies. The aim of this study was to evaluate prognostic factors that influence survival in patients with metastatic melanoma to the brain treated with SRS.

METHODS This retrospective analysis included all patients with melanoma brain metastases treated with SRS at the University of Southern California between 1994 and 2015. For the entire cohort, the authors performed a multivariable Cox regression analysis with an end point of survival. Covariates included number of lesions, total intracranial tumor volume, age, sex, and treatment date prior to 2005 or 2005 onward.

In the subset of patients with > 1 lesion, additional multivariable Cox regression was performed, with covariates of Karnofsky Performance Scale, Graded Prognostic Assessment, Recursive Partitioning Analysis, timing of metastases (synchronous/metachronous), change in lesion number, and previous whole-brain radiation therapy or resection in addition to the previously mentioned covariates. Overall survival (OS) was calculated from the day SRS was performed to the date of last follow-up or date of death.

RESULTS A total of 401 patients were available for analysis. The median follow-up was 35.1 months for patients alive at the time of analysis, and the median OS was 7.7 months for the entire cohort (95\% Cl 6.7-8.3 months). In the entire cohort, greater number of brain lesions, higher total intracranial tumor volume, age $>50$ years, treatment prior to 2005, and male sex were found to be statistically significant factors associated with worse survival. The strongest risk factors for decreased OS were tumor volume $>10 \mathrm{~cm}^{3}$ and $\geq 5$ lesions, with hazard ratios for risk of death of 1.7 and 2.2 , respectively. In the subset of patients with $>1$ lesion, tumor volume $>10 \mathrm{~cm}^{3}$ and no resection were the only factors significantly associated with decreased OS, with hazard ratios of 1.9 and 2.0 (hazard ratio of 0.49 for resection), respectively.

CONCLUSIONS This study suggests that greater lesion number, higher intracranial tumor volume, older age, treatment prior to 2005, and male sex have prognostic significance for decreased OS in patients with melanoma brain metastases treated with SRS. Additionally, in the subset of patients with > 1 lesion, only higher total tumor volume and no resection were associated with worse survival.

http://thejns.org/doi/abs/10.3171/2016.8.GKS161359

KEY WORDS melanoma; metastases; brain; stereotactic radiosurgery; radiation; prognostic; oncology

$\mathrm{M}$ ELANOMA is the sixth most frequent invasive cancer in the US. ${ }^{23}$ The incidence has doubled over the last 40 years, with more than 76,000 new cases accounting for upward of 10,000 deaths per year in the US. ${ }^{23}$ Melanoma has one of the highest rates of brain metastases of all malignancies. Seven percent of patients with melanoma have brain metastases at diagnosis, and more than one-third of patients will develop clinically apparent brain metastases. ${ }^{3}$ Cases of melanoma brain metastases account for $10 \%$ of all newly diagnosed brain

ABBREVIATIONS GPA = graded prognostic assessment; HR = hazard ratio; KPS = Karnofsky Performance Scale; OS = overall survival; RPA = recursive partitioning analysis; $\mathrm{SRS}=$ stereotactic radiosurgery; $\mathrm{WBRT}=$ whole-brain radiation therapy.

SUBMITTED June 9, 2016. ACCEPTED August 2, 2016.

INCLUDE WHEN CITING DOI: 10.3171/2016.8.GKS161359. 
metastases. ${ }^{15}$ The median survival time for patients with melanoma brain metastases is 4-6 months..$^{8,24}$

Stereotactic radiosurgery (SRS) is becoming increasingly used in the treatment of brain metastases because it is associated with a lower risk of developing neurocognitive decline and a higher rate of local tumor control compared with whole-brain radiation therapy (WBRT). ${ }^{5}$ This is especially important for melanoma, which is historically classified as radioresistant, and often suboptimally controlled with WBRT alone. ${ }^{7}$

The total number of intracranial metastases is one important criterion that is routinely used to evaluate a patient's suitability for SRS, with the upper limit traditionally set at 3 or 4 lesions. ${ }^{1,19}$ However, recent studies suggest that lesion number may not be a significant prognostic factor for overall survival (OS) in patients with brain metastases. $4,6,21,32$

Due to the paucity of studies in the literature directly addressing the importance of lesion number relative to total intracranial volume in patients with melanoma, we performed this study with an exclusive focus on melanoma, to evaluate survival in patients with melanoma brain metastases treated with SRS as it relates to prognostic factors including lesion number, total tumor volume, age, and sex.

\section{Methods \\ Data Collection}

We retrospectively reviewed records of patients who were consecutively treated with SRS between 1994 and 2015. These patients were all diagnosed with metastatic melanoma to the brain and treated with SRS at Keck Hospital of the University of Southern California (formerly USC University Hospital). This study includes all patients from the 2002 report by $\mathrm{Yu}$ et al. ${ }^{33}$ We obtained patient survival data from the cancer registry and by chart review. Our study was approved by the hospital's institutional review board.

\section{Patient Population and Treatment Procedures}

All patients were treated with single-fraction Gamma Knife radiosurgery. Gamma Knife (Elekta Instruments, Inc.) model $\mathrm{U}$, model $\mathrm{C}$, and Perfexion were used during the time ranges of 1994-2000, 2000-2008, and 2008 to present, respectively. All patients were immobilized with a Leksell Gamma Knife stereotactic head frame. The frame application was done while the patient was under conscious sedation provided by an anesthesia team. MR images of the brain were acquired immediately after frame application for treatment planning on the GammaPlan computer, and Gamma Knife treatment was performed the same day.

\section{Statistical Analysis}

Overall survival was the primary end point, which was defined as the time period from the day of SRS to death. If patients were still alive or lost to follow-up, OS was censored at the last date known to be alive. For the entire cohort, we performed Kaplan-Meier estimates, univariable log-rank tests, and multivariable Cox regression analyses with covariates including lesion number, total tumor vol- ume, age, sex, and treatment period. Lesion number was defined as the number of lesions treated during the initial Gamma Knife session and was divided into 1 lesion, 2-4 lesions, and $\geq 5$ lesions. Total tumor volume was defined as the total volume of tumors treated as measured by MRI on the day of Gamma Knife treatment. Age was dichotomized as younger than 50 and 50 years or older. Treatment period was divided into prior to 2005 and 2005 and later. We chose 2005 as a cutoff because this marked the beginning of the initial pivotal Phase III trial that showed improved survival with the first immunotherapy agent, ipilimumab, in the treatment of metastatic melanoma. ${ }^{13}$ Additionally, a restricted cubic spline was used to model the relationship between age and OS.

In the subset of patients with $>1$ lesion, additional univariable log-rank tests and multivariable Cox regression were performed with covariates of Karnofsky Performance Scale (KPS), graded prognostic assessment (GPA), recursive partitioning analysis (RPA), timing of metastases, change in lesion number, and history of WBRT or resection in addition to the previously mentioned covariates. KPS was scored from 0 to 100 . The GPA was scored from 0 to 4 based on age, KPS score, number of cranial metastases, and presence of extracranial metastases. ${ }^{31}$ RPA was assigned a value from I to III based on KPS score, age, whether primary disease was controlled, and presence of extracranial metastases. ${ }^{9}$ Timing of metastases was divided into synchronous (metastasis diagnosed at the same time as primary disease) or metachronous (metastasis diagnosed after diagnosis of primary disease). Change in lesion number was defined as an increase in the number of metastases at initial consultation when compared with lesions found on the day of treatment. Resection and WBRT were noted if they were completed prior to Gamma Knife treatment.

SAS 9.4 (SAS Institute) was used to perform the analyses. All tests were 2 sided at a significance level of 0.05 .

\section{Results}

A total of 401 patients with 1023 lesions from metastatic melanoma were treated with SRS at the University of Southern California between 1994 and 2015. In our cohort, there were 274 men and 127 women. Two hundred fifty-six patients were treated prior to 2005 and 145 were treated in 2005 or later. The mean age at the time of SRS treatment was 58 years (range $22-88$ years). The mean number of brain metastases treated across all patients was 2.5 (range 1-16).

The median marginal dose was 18 Gy (range 12-22 Gy). The mean prescribed isodose line was $60 \%$ (range $50 \%-90 \%$ ). The mean tumor volume was $4.9 \mathrm{~cm}^{3}$ (range 0.01-32.7 $\mathrm{cm}^{3}$ ). Patient demographic data and treatment characteristics are shown in Table 1 . The median OS was 7.7 months for the entire cohort (95\% CI 6.7-8.3). The median follow-up was 35.1 months (range 1 month to 17 years) for patients alive at time of analysis.

On multivariable trend analysis for the entire cohort, greater lesion number, higher lesion volume, age, male sex, and treatment prior to 2005 had significant negative associations with OS, as shown in Table 2. Patients un- 
TABLE 1. Demographic data and treatment characteristics of 401 patients

\begin{tabular}{ccc}
\hline Variable & No. of Patients & $\%$ \\
\hline Age, yrs & & \\
\hline$<50$ & 112 & 28 \\
\hline $50-59$ & 107 & 28 \\
\hline $60-69$ & 86 & 22 \\
\hline$\geq 70$ & 83 & 21 \\
\hline Sex & & \\
\hline F & 127 & 32 \\
\hline M & 274 & 68 \\
\hline No. of lesions & & \\
\hline 1 & 188 & 47 \\
\hline $2-4$ & 157 & 44 \\
\hline$\geq 5$ & 56 & 92 \\
\hline Tumor vol, cm ${ }^{3}$ & & 19 \\
\hline$<5$ & 266 & 14 \\
\hline $5-10$ & 74 & 5 \\
\hline$>10-20$ & 47 &
\end{tabular}

der the age of 50 years had a median OS of 8.8 months compared with 7.1 months for patients 50 years or older. Women had a median OS of 9.0 months compared with 6.6 months for men. Patients with 1 lesion had a median OS of 8.4 months compared with 7.7 months for those with 2-4 lesions, and 4.9 months for patients with $\geq 5$ lesions. The median OS was 8.2 months for patients with tumor volume $<5 \mathrm{~cm}^{3}$ compared with 6.9 months for those with tumor volume $5-10 \mathrm{~cm}^{3}$ and 5.9 months for those with tumor volume $>10 \mathrm{~cm}^{3}$. Patients treated in 2005 or later had a median OS of 8.0 months compared with 7.4 months in patients treated between 1994 and 2004.

Kaplan-Meier curves for survival are shown in Fig. 1. When the hazard ratio (HR) for OS was plotted against age using the restricted cubic spline model, we found that the relationship between age and OS was nonlinear (Fig. 2). The lowest HR of death was found in patients between the ages of 35 and 50 years, and the highest HR was observed in patients younger than 30 and older than 80 years. For the entire cohort, the strongest determinants of a shortened OS were $\geq 5$ brain metastases, with an HR of $2.2(\mathrm{p}<0.001)$, and total intracranial tumor volume $>$ $10 \mathrm{~cm}^{3}$, with an HR of $1.7(\mathrm{p}=0.002)$.

For the subset of patients with $>1$ lesion, univariable analysis showed significant associations between greater lesion number, higher tumor volume, lower GPA score, and synchronous brain metastases and decreased OS. On multivariable analysis, only higher tumor volume and absence of prior resection remained statistically significant for worsened OS, with an HR of 1.9 for both total intracranial tumor volumes of $5-10 \mathrm{~cm}^{3}$ and $>10 \mathrm{~cm}^{3}$ versus $<5 \mathrm{~cm}^{3}(\mathrm{p}<0.001)$ and an HR of 0.49 for resection ( $\mathrm{p}$ $=0.002$ ). Lesion number was of borderline significance, with an HR of 1.38 for $\geq 5$ brain metastases $(\mathrm{p}=0.09)$. Results for this cohort are shown in Table 3.

\section{Discussion}

Stereotactic radiosurgery is commonly used in the management of melanoma brain metastases, given the higher rates of local control for this radioresistant histology and decreased cognitive side effects compared with WBRT. Total lesion number, which is easily determined, is one of the major selection criteria for deciding which patients should undergo SRS versus WBRT for initial management of brain metastases. Limiting the use of SRS

TABLE 2. Prognostic factors for OS among 401 patients with melanoma brain metastases treated with SRS

\begin{tabular}{|c|c|c|c|c|c|}
\hline Variable & No. of Patients & Median OS, Mos (95\% Cl) & 2-Yr Survival Rate \pm SE & $\mathrm{HR}(95 \% \mathrm{Cl})^{*}$ & p Value* \\
\hline Age, yrs & & & & & 0.038 \\
\hline$<50$ & 116 & $8.8(7.1-12.0)$ & $0.21 \pm 0.04$ & 1.00 (reference) & \\
\hline$\geq 50$ & 285 & $7.1(6.5-8.0)$ & $0.14 \pm 0.02$ & $1.29(1.01-1.64)$ & \\
\hline Sex & & & & & 0.009 \\
\hline$F$ & 127 & $9.0(8.0-11.6)$ & $0.20 \pm 0.04$ & 1.00 (reference) & \\
\hline M & 274 & $6.6(5.7-7.7)$ & $0.15 \pm 0.02$ & $1.36(1.08-1.71)$ & \\
\hline No. of Lesions & & & & & $<0.001$ \\
\hline 1 & 188 & $8.4(6.9-10.4)$ & $0.21 \pm 0.03$ & 1.00 (reference) & \\
\hline $2-4$ & 157 & $7.7(6.4-8.5)$ & $0.13 \pm 0.03$ & $1.25(0.99-1.58)$ & \\
\hline$\geq 5$ & 56 & $4.9(3.8-7.6)$ & $0.08 \pm 0.04$ & $2.18(1.56-3.03)$ & \\
\hline Total tumor vol, $\mathrm{cm}^{3}$ & & & & & 0.002 \\
\hline$<5$ & 266 & $8.2(7.5-9.2)$ & $0.19 \pm 0.02$ & 1.00 (reference) & \\
\hline $5-10$ & 74 & $6.9(5.5-9.9)$ & $0.12 \pm 0.04$ & $1.33(1.01-1.77)$ & \\
\hline$>10$ & 61 & $5.9(4.0-7.1)$ & $0.07 \pm 0.04$ & $1.66(1.23-2.25)$ & \\
\hline Treatment period & & & & & 0.001 \\
\hline 1994-2004 & 256 & $7.4(6.5-8.2)$ & $0.12 \pm 0.02$ & 1.00 (reference) & \\
\hline 2005-2015 & 145 & $8.0(6.7-10.7)$ & $0.25 \pm 0.04$ & $0.68(0.54-0.86)$ & \\
\hline
\end{tabular}

\footnotetext{
* Based on the multivariable Cox regression model adjusted for the variables in the table.
} 

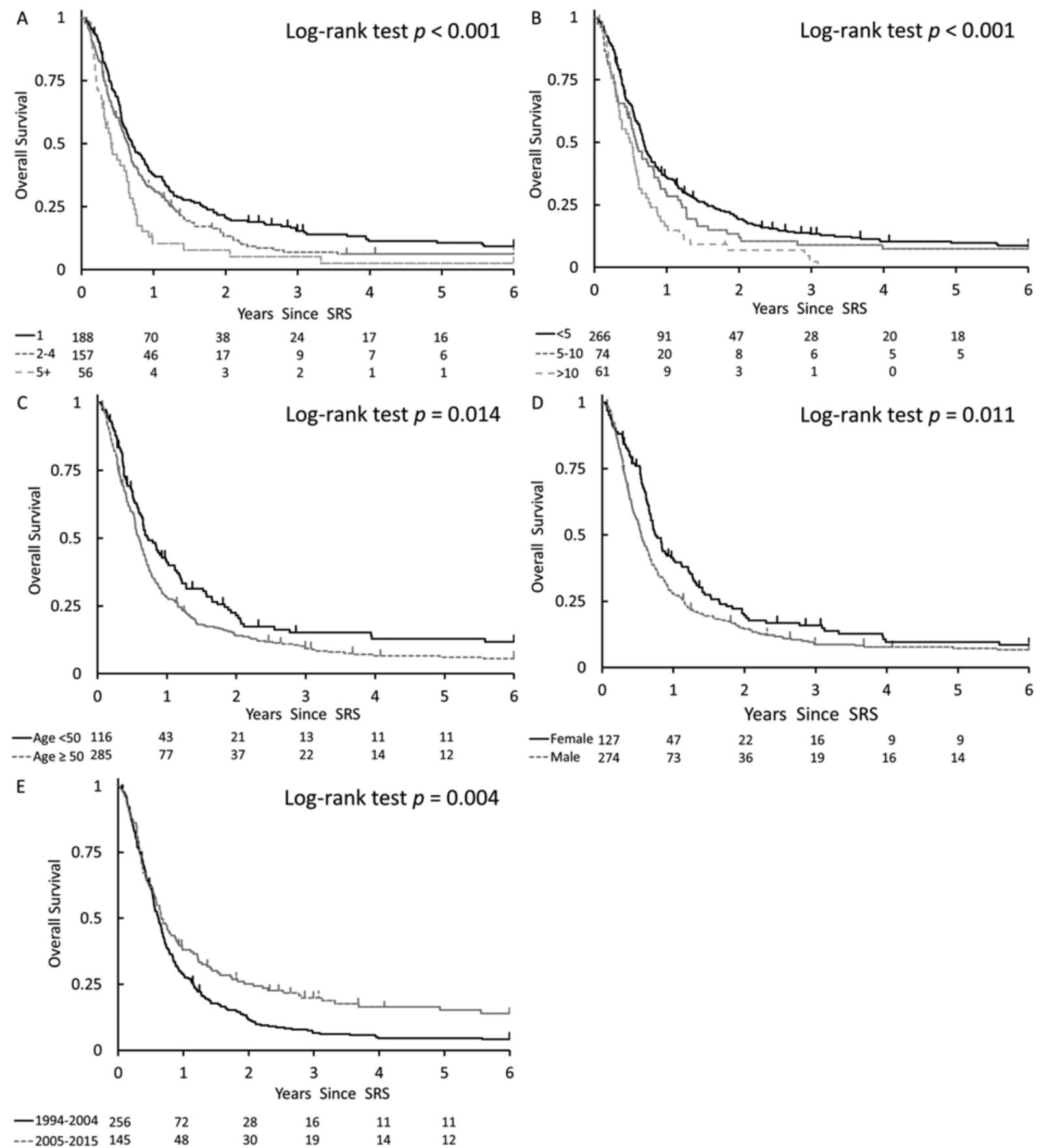

FIG 1. Kaplan-Meier curves for OS stratified by lesion number (A), total intracranial tumor volume ( $\left.\mathrm{cm}^{3}\right)(B)$, age (C), sex (D), and treatment period $(\mathbf{E})$.

exclusively for 1-3 brain metastases historically has been widely accepted, ${ }^{7}$ but this restriction has been called into question by recent publications, both prospective and retrospective.

Recently, Yamamoto et al. conducted a prospective multicenter registry trial in Japan that evaluated more than 1000 patients with brain metastases from a variety of cancers and found no difference in survival between patients presenting with 2-4 lesions and those with $\geq 5$ lesions. ${ }^{32}$ Less than $3 \%$ of patients had melanoma in this series. Similarly, in a study by Chang et al., 323 patients with brain metastases were evaluated; no difference in survival was seen between patients with 1-5 lesions, 6-10 lesions, and 11-15 lesions. ${ }^{6}$ In this study, less than $15 \%$ of patients had melanoma. Other publications by Bhatnagar et al. and Likhacheva et al. evaluated more than 200 patients with brain metastases and found that the total number of lesions was not a statistically significant prognostic factor for OS on multivariable analysis, but that other factors such as age, performance status, and total intracranial 


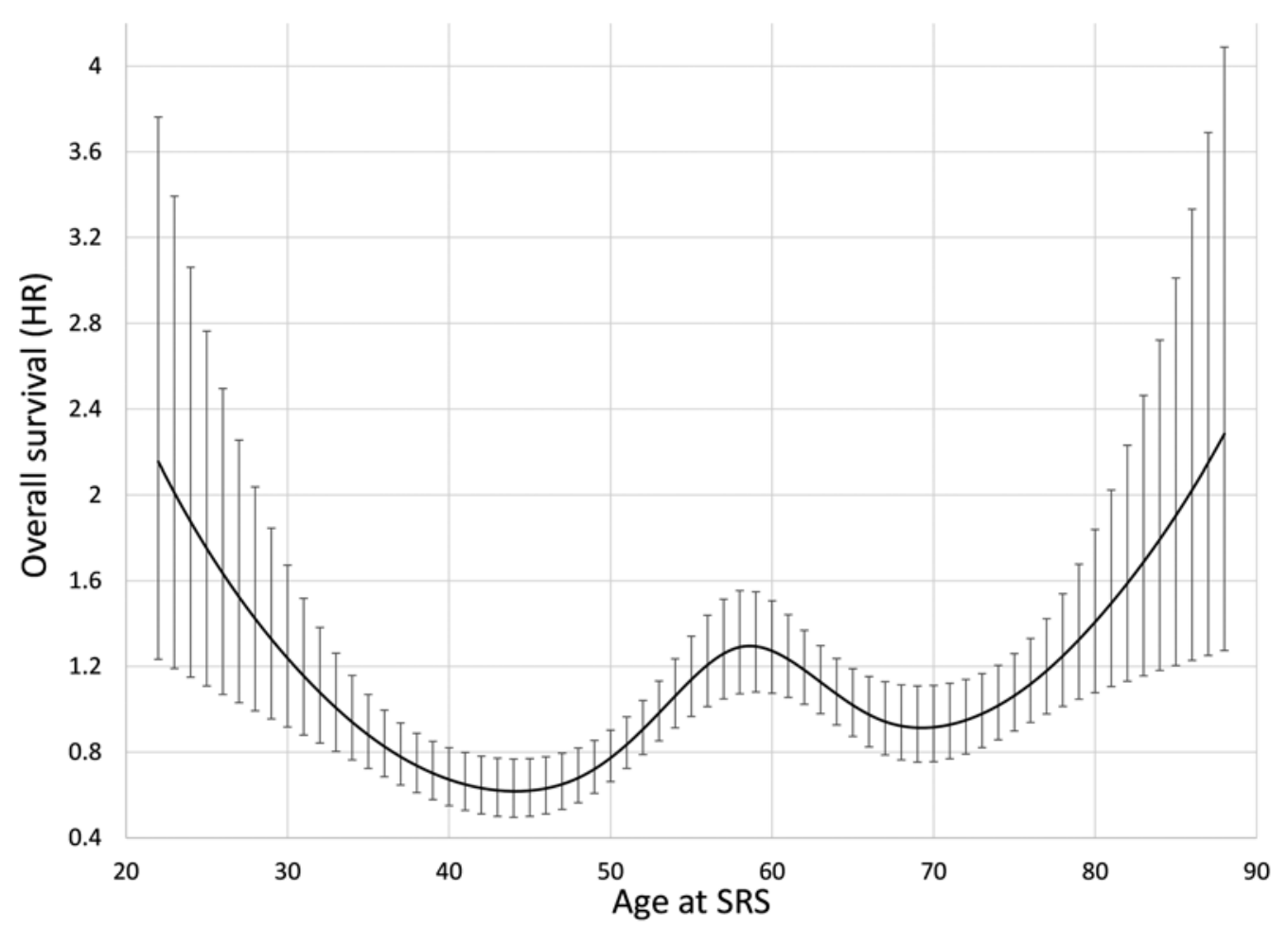

FIG 2. Restricted cubic spline model evaluating the relationship between age and OS.

tumor volume were prognostic.,21 Again, patients with melanoma comprised no more than $30 \%$ of the patients in these studies. It is important to note that the majority of patients had lung or breast cancer histologic types, which have historically not been considered radioresistant.

Treatment of patients with melanoma with multiple brain metastases requires individualized clinical decision making, taking into account multiple other patient factors. We found in our cohort of only patients with melanoma that worse survival was associated with $\geq 5$ brain metastases (HR 2.2), tumor volume $>10 \mathrm{~cm}^{3}$ (HR 1.7), age older than 50 years (HR 1.3), male sex (HR 1.4), and treatment era 1994-2004 (HR 1.5). There was a stronger association between survival and lesion number in our study, compared with the previously mentioned brain metastases cohorts, possibly because melanoma is not as radiosensitive as other histologic types.

We also found that patients younger than 50 years lived longer than those 50 years or older. This finding is consistent with the meta-analysis of 3 randomized trials evaluating SRS with or without WBRT in patients with 1-4 brain metastases. ${ }^{27}$ Sahgal et al. found that age 50 years and younger was a significant effect modifier of survival in patients who received SRS alone, with a higher rate of distant brain metastases for patients older than 50 years. This study, however, included a majority of lung and breast cancer histologic types. Although younger age was associated with a better prognosis overall in our cohort, we found that the relationship was more complex. When age and survival probability are plotted together, there is a peak in survival at ages $35-50$ years, with both younger and older patients experiencing decreasing survival at the far extremes of the age range (Fig. 2).
This phenomenon was previously reported by Balch et al. in an analysis of 28,047 patients with melanoma from the American Joint Committee on Cancer melanoma staging database. ${ }^{2}$ Patients younger than 20 years and older than 70 years had worse survival and were also found to have more clinically aggressive features. Older age is often cited as a negative prognostic factor and attributed to the higher likelihood of comorbidities, fragility, and decreased immunity. The mechanism of poorer outcomes in young adults, however, is more nebulous and may be partially explained by a higher rate of $B R A F \mathrm{mu}-$ tation, which has been associated with more aggressive disease. ${ }^{12}$

Our sex finding is consistent with the available literature, showing worse outcomes for male patients even after accounting for stage of disease and other patient factors. Joosse et al. evaluated a total of 11,774 patients with all stages of melanoma from the Munich Cancer Registry in Germany and found that 10 -year OS was significantly higher in female patients, with an HR of 0.69 after accounting for age, year of diagnosis, primary tumor Breslow thickness, histology, body site, N-stage, and M-stage. ${ }^{17}$ Furthermore, in a pooled analysis of 2734 patients with Stage III and IV melanoma from 3 randomized controlled trials from the European Organisation for Research and Treatment of Cancer, female patients had significantly improved results in all end points, including OS, diseasespecific survival, progression-free survival, and time to distant metastases. ${ }^{16}$ Although the mechanism is unclear, there are hypotheses that this could be due to disparities in seeking treatment, worse tumor biology, or different host influences that may be hormonally based. ${ }^{11,30}$ In the subset of patients with melanoma with brain metastases, the 
TABLE 3. Prognostic factors for OS among 213 patients with > 1 melanoma brain metastases treated with SRS

\begin{tabular}{|c|c|c|c|c|c|c|}
\hline Variable & No. of Patients & Median OS in Mos $(95 \% \mathrm{Cl})$ & $\operatorname{HR}(95 \% \mathrm{Cl})^{*}$ & p Value ${ }^{*}$ & $\mathrm{HR}(95 \% \mathrm{Cl}) \dagger$ & $\mathrm{p}$ Value $†$ \\
\hline Age, yrs & & & & 0.16 & & 0.35 \\
\hline$<50$ & 57 & $7.7(5.9-8.8)$ & 1.00 (reference) & & 1.00 (reference) & \\
\hline$\geq 50$ & 156 & $6.6(5.1-8.0)$ & $1.27(0.91-1.78)$ & & $1.20(0.82-1.77)$ & \\
\hline Sex & & & & 0.26 & & 0.20 \\
\hline$F$ & 64 & $8.1(7.2-10.1)$ & 1.00 (reference) & & 1.00 (reference) & \\
\hline M & 149 & $5.7(4.5-7.6)$ & $1.20(0.87-1.65)$ & & $1.25(0.89-1.76)$ & \\
\hline No. of lesions & & & & 0.009 & & 0.09 \\
\hline $2-4$ & 157 & $7.7(6.4-8.5)$ & 1.00 (reference) & & 1.00 (reference) & \\
\hline$\geq 5$ & 56 & $4.9(3.8-7.6)$ & $1.53(1.10-2.14)$ & & $1.38(0.95-1.99)$ & \\
\hline Total tumor vol, $\mathrm{cm}^{3}$ & & & & 0.002 & & $<0.001$ \\
\hline$<5$ & 144 & $8.0(6.6-9.1)$ & 1.00 (reference) & & 1.00 (reference) & \\
\hline $5-10$ & 37 & $3.6(2.2-7.1)$ & $1.68(1.14-2.47)$ & & $1.94(1.30-2.88)$ & \\
\hline$>10$ & 32 & $4.5(2.8-7.3)$ & $1.78(1.16-2.72)$ & & $1.87(1.16-3.02)$ & \\
\hline Treatment period & & & & 0.13 & & 0.059 \\
\hline 1994-2004 & 131 & $7.1(5.4-8.1)$ & 1.00 (reference) & & 1.00 (reference) & \\
\hline $2005-2015$ & 82 & $7.1(4.5-8.3)$ & $0.80(0.59-1.08)$ & & $0.72(0.51-1.01)$ & \\
\hline KPS score & & & & 0.078 & & 0.23 \\
\hline $90-100$ & 108 & $8.1(6.9-9.4)$ & 1.00 (reference) & & 1.00 (reference) & \\
\hline 80 & 33 & $4.8(3.4-8.0)$ & $1.36(0.90-2.05)$ & & $1.19(0.74-1.91)$ & \\
\hline $50-70$ & 22 & $4.3(3.4-7.3)$ & $1.64(0.99-2.70)$ & & $1.71(0.93-3.14)$ & \\
\hline Unknown & 50 & Excluded & & & & \\
\hline GPA score & & & & 0.035 & & 0.17 \\
\hline $0.5-1$ & 40 & $4.6(3.4-7.3)$ & 1.00 (reference) & & 1.00 (reference) & \\
\hline $1.5-2$ & 82 & $6.4(4.8-8.1)$ & $0.81(0.54-1.21)$ & & $1.14(0.68-1.94)$ & \\
\hline $2.5-3.5$ & 40 & $9.4(8.0-13.3)$ & $0.54(0.33-0.88)$ & & $0.74(0.40-1.38)$ & \\
\hline Unknown & 51 & & & & & \\
\hline RPA class & & & & 0.12 & & 0.68 \\
\hline 1 & 21 & $10.2(4.2-18.9)$ & 1.00 (reference) & & 1.00 (reference) & \\
\hline ॥ & 134 & $6.9(5.4-7.9)$ & $1.42(0.85-2.36)$ & & $1.09(0.57-2.07)$ & \\
\hline III & 8 & $4.3(3.4-7.3)$ & $2.44(1.00-5.98)$ & & $1.64(0.53-5.09)$ & \\
\hline Unknown & 50 & Excluded & & & & \\
\hline Timing of metastases & & & & $<0.001$ & & 0.11 \\
\hline Metachronous & 128 & $7.9(6.4-9.3)$ & 1.00 (reference) & & 1.00 (reference) & \\
\hline Synchronous & 13 & $4.6(1.5-7.3)$ & $2.69(1.43-5.04)$ & & $1.84(0.87-3.90)$ & \\
\hline Unknown & 72 & Excluded & & & & \\
\hline Change in no. of lesions & & & & 0.41 & & 0.13 \\
\hline No & 77 & $8.1(6.3-10.1)$ & 1.00 (reference) & & 1.00 (reference) & \\
\hline Yes & 60 & $6.4(4.5-7.9)$ & $1.16(0.80-1.68)$ & & $1.43(0.90-2.25)$ & \\
\hline Unknown & 76 & Excluded & & & & \\
\hline WBRT & & & & 0.37 & & 0.79 \\
\hline No & 134 & $7.5(6.4-8.3)$ & 1.00 (reference) & & 1.00 (reference) & \\
\hline Yes & 15 & $5.4(2.8-9.3)$ & $1.28(0.75-2.19)$ & & $0.91(0.45-1.83)$ & \\
\hline Unknown & 64 & Excluded & & & & \\
\hline Resection & & & & 0.054 & & 0.002 \\
\hline No & 114 & $6.6(5.0-7.7)$ & 1.00 (reference) & & 1.00 (reference) & \\
\hline Yes & 40 & $9.4(7.3-17.2)$ & $0.68(0.46-1.02)$ & & $0.49(0.31-0.78)$ & \\
\hline Unknown & 59 & Excluded & & & & \\
\hline
\end{tabular}

* Based on the univariable analysis and log-rank test.

$\dagger$ Based on the multivariable Cox regression model adjusted for the variables in the table. 
TABLE 4. Selected melanoma SRS series from the literature

\begin{tabular}{|c|c|c|c|c|c|c|c|}
\hline Authors \& Year & Study Yrs & Institution & $\begin{array}{c}\text { No. of } \\
\text { Patients }\end{array}$ & $\begin{array}{l}\text { No. of Brain } \\
\text { Metastases }\end{array}$ & $\begin{array}{l}\text { Margin } \\
\text { Dose, Gy }\end{array}$ & $\begin{array}{l}\text { No. of Lesions/ } \\
\text { Survival, Mos }\end{array}$ & $\begin{array}{l}\text { Median } \\
\text { OS, Mos }\end{array}$ \\
\hline Mingione et al., 2002 & 1989-1999 & University of Virginia & 45 & 92 & $13-25$ & $1 / 14.5 ; \geq 2 / 7.6$ & 10.5 \\
\hline Selek et al., 2004 & $1991-2001$ & $\begin{array}{l}\text { University of Texas MD Ander- } \\
\text { son Cancer Center }\end{array}$ & 103 & 153 & $10-24$ & $1 / 7.2 ; \geq 2 / 5.0$ & 6.7 \\
\hline Radbill et al., 2004 & 1996-2001 & University of Alabama & 51 & 188 & $10-21$ & $1 / 18 ; \geq 2 / 4.7$ & 6.1 \\
\hline $\begin{array}{l}\text { Gaudy-Marqueste et } \\
\text { al., } 2006\end{array}$ & 1997-2003 & $\begin{array}{l}\text { Hopital la Timone, Marseille, } \\
\text { France }\end{array}$ & 106 & 221 & $14-40$ & $1 / 5.5 ; \geq 2 / 4.6$ & 5.9 \\
\hline Skeie et al., 2011 & 1996-2006 & $\begin{array}{l}\text { Haukeland University Hospital, } \\
\text { Norway }\end{array}$ & 77 & 143 & $15-25$ & $1 / 10 ; \geq 2 / 6$ & 7.0 \\
\hline Liew et al., 2011 & 1987-2008 & University of Pittsburgh & 333 & 1570 & $10-22$ & $1-2 / 6.7 ; 3-6 / 4.3 ; \geq 7 / 2.8$ & 5.6 \\
\hline Present study & 1994-2015 & University of Southern California & 401 & 1023 & $12-22$ & $1 / 8.4 ; 2-4 / 7.7 ; \geq 5 / 4.9$ & 7.7 \\
\hline
\end{tabular}

sex disparity is not well established, although reported in some small retrospective series; ${ }^{14,18}$ further investigation is warranted.

In our cohort, patient survival was slightly higher in the current era (2005-2015) compared with the decade prior (1994-2004). Because our Gamma Knife procedures, targeting, and prescriptions have not changed significantly over time, we attribute the lower HR of 1.5 of being treated in the first decade to the development of new systemic agents for melanoma not having yet occurred. The past decade has seen the advent of multiple novel systemic agents, specifically immunotherapy agents including CTLA-4 and PD-1 inhibitors, which have shown significant survival benefits for patients with metastatic melanoma. ${ }^{13,24}$

Although there are few large SRS series including only patients with melanoma, the available literature mostly supports our conclusions regarding the prognostic significance of lesion number and tumor volume. A summary of selected studies is shown in Table 4.

In the largest series, from the University of Pittsburgh, the authors found the longest survival of 54.3 months in patients with $\leq 8$ lesions, RPA Class I-II, and no WBRT. ${ }^{20}$ On multivariable analysis, extracranial disease status, KPS score, number of lesions, prior WBRT, chemotherapy, immunotherapy, and hemorrhagic metastases were important prognostic factors for survival. Total intracranial tumor volume was not included. However, total radiosurgical volume, which can serve as a surrogate for intracranial tumor volume, was not significantly associated with survival. In a French study, Gaudy-Marqueste ${ }^{10}$ et al. found favorable prognostic factors for survival to be KPS score $>80$, cortical or subcortical location, solitary brain metastasis, and a score index for radiosurgery that incorporates age, KPS score, systemic disease, number of metastases, and volume of metastases.

Similarly, in an experience from MD Anderson Cancer Center, Selek et al. found that single brain metastasis was the only factor with a significant effect on distant brain metastasis-free survival, and score index for radiosurgery was the only factor with a significant effect on OS. ${ }^{28}$ Additionally, a Norwegian study by Skeie et al. found on multivariable analysis that no extracranial disease, tumor volume $<5 \mathrm{~cm}^{3}$, RPA Class I, and solitary metastasis were significant factors affecting survival. ${ }^{29}$ Finally, Radbill et al., from the University of Alabama, found that RPA Class II-III, infratentorial location, and multiple lesions were prognostic for decreased survival. ${ }^{25}$

Given that multiple studies in the literature have found significance in lesion number (specifically between a single lesion and multiple lesions), we hypothesized that the significant association between lesion number and survival may be driven by patients with a single metastasis.

Along these lines, we performed an in-depth analysis of patients with $>1$ lesion at the time of radiosurgery. In this subgroup, lesion number was no longer a significant factor for OS on multivariable analysis taking into account a multitude of other patient and treatment factors including KPS score, GPA score, RPA class, timing of metastases, increase in number of lesions detected from time of consultation to treatment, and the performance of resection or prior WBRT. Only lesion volume and prior resection remained significant prognostic factors for OS. This highlights the prognostic value of lesion volume in the subset of patients presenting with multiple brain metastases. Although lesion number is still an important factor to consider, total tumor volume may drive survival more than lesion number alone. Additionally, this also emphasizes the importance of resection, especially for larger and/or symptomatic lesions when possible.

Other risk factors, including KPS score, GPA score, RPA class, timing of metastases, change in lesion number, and prior WBRT, lost statistical significance for OS in the subgroup of patients presenting with multiple brain metastases. Although they lost statistical significance, this does not preclude the importance of these other prognostic factors, because the smaller subgroup may not be sufficiently powered to reach statistical significance for these factors.

In the era of new systemic therapies that prolong OS in patients with metastatic melanoma, the decision to treat brain metastases with SRS versus WBRT becomes increasingly complex. A variety of factors, including but not limited to lesion number, should be evaluated when making treatment decisions.

Limitations of the present study include its retrospective nature. For the majority of our patients, we were unable to determine whether the cause of death was from 
intracranial progression, systemic disease, or other causes. Many patients were referred from different institutions and returned to their primary providers after receiving radiosurgery and lacked imaging follow-up near end of life. Although we controlled for certain confounding factors, there may be other factors influencing survival that we did not account for. Additionally, our subgroup analyses may not have had sufficient power to detect significance in certain prognostic factors. As systemic therapy changes the paradigm of melanoma treatment, there will be a need to explore the interaction of novel systemic therapies on SRS in terms of safety, examine the effectiveness of SRS to the treated brain metastasis, and characterize neuroimaging findings of brain metastases managed with both SRS and novel systemic agents.

\section{Conclusions}

To our knowledge, this is one of the largest melanoma SRS series conducted to date. Our study suggests prognostic significance for OS related to lesion number, total intracranial tumor volume, age, sex, and treatment era. Importantly, in the setting of multiple brain metastases at presentation, we found that tumor volume and resection remained statistically significant for OS. Total intracranial tumor volume, in addition to lesion number, should be assessed and used as selection factors when assessing patients with melanoma brain metastases for possible SRS.

\section{References}

1. Andrews DW, Scott CB, Sperduto PW, Flanders AE, Gaspar LE, Schell MC, et al: Whole brain radiation therapy with or without stereotactic radiosurgery boost for patients with one to three brain metastases: phase III results of the RTOG 9508 randomised trial. Lancet 363:1665-1672, 2004

2. Balch CM, Soong SJ, Gershenwald JE, Thompson JF, Coit DG, Atkins MB, et al: Age as a prognostic factor in patients with localized melanoma and regional metastases. Ann Surg Oncol 20:3961-3968, 2013

3. Barnholtz-Sloan JS, Sloan AE, Davis FG, Vigneau FD, Lai P, Sawaya RE: Incidence proportions of brain metastases in patients diagnosed (1973 to 2001) in the Metropolitan Detroit Cancer Surveillance System. J Clin Oncol 22:2865-2872, 2004

4. Bhatnagar AK, Flickinger JC, Kondziolka D, Lunsford LD: Stereotactic radiosurgery for four or more intracranial metastases. Int J Radiat Oncol Biol Phys 64:898-903, 2006

5. Chang EL, Wefel JS, Hess KR, Allen PK, Lang FF, Kornguth DG, et al: Neurocognition in patients with brain metastases treated with radiosurgery or radiosurgery plus whole-brain irradiation: a randomised controlled trial. Lancet Oncol 10:1037-1044, 2009

6. Chang WS, Kim HY, Chang JW, Park YG, Chang JH: Analysis of radiosurgical results in patients with brain metastases according to the number of brain lesions: is stereotactic radiosurgery effective for multiple brain metastases? J Neurosurg 113 Suppl:73-78, 2010

7. Douglas JG, Margolin K: The treatment of brain metastases from malignant melanoma. Semin Oncol 29:518-524, 2002

8. Fife KM, Colman MH, Stevens GN, Firth IC, Moon D, Shannon KF, et al: Determinants of outcome in melanoma patients with cerebral metastases. J Clin Oncol 22:1293-1300, 2004

9. Gaspar L, Scott C, Rotman M, Asbell S, Phillips T, Wasserman T, et al: Recursive partitioning analysis (RPA) of prognostic factors in three Radiation Therapy Oncology Group
(RTOG) brain metastases trials. Int J Radiat Oncol Biol Phys 37:745-751, 1997

10. Gaudy-Marqueste C, Regis JM, Muracciole X, Laurans R, Richard MA, Bonerandi JJ, et al: Gamma-Knife radiosurgery in the management of melanoma patients with brain metastases: a series of 106 patients without whole-brain radiotherapy. Int J Radiat Oncol Biol Phys 65:809-816, 2006

11. Gupta S, Artomov M, Goggins W, Daly M, Tsao H: Gender disparity and mutation burden in metastatic melanoma. J Natl Cancer Inst 107:10-13, 2015

12. Hacker E, Hayward NK, Dumenil T, James MR, Whiteman DC: The association between MC1R genotype and BRAF mutation status in cutaneous melanoma: findings from an Australian population. J Invest Dermatol 130:241-248, 2010

13. Hodi FS, O'Day SJ, McDermott DF, Weber RW, Sosman JA, Haanen JB, et al: Improved survival with ipilimumab in patients with metastatic melanoma. N Engl J Med 363:711723, 2010

14. Hofmann MA, Coll SH, Küchler I, Kiecker F, Wurm R, Sterry W, et al: Prognostic factors and impact of treatment in melanoma brain metastases: better prognosis for women? Dermatology 215:10-16, 2007

15. Johnson JD, Young B: Demographics of brain metastasis. Neurosurg Clin N Am 7:337-344, 1996

16. Joosse A, Collette S, Suciu S, Nijsten T, Patel PM, Keilholz $\mathrm{U}$, et al: Sex is an independent prognostic indicator for survival and relapse/progression-free survival in metastasized stage III to IV melanoma: a pooled analysis of five European Organisation for Research and Treatment of Cancer randomized controlled trials. J Clin Oncol 31:2337-2346, 2013

17. Joosse A, de Vries E, Eckel R, Nijsten T, Eggermont AMM, Hölzel D, et al: Gender differences in melanoma survival: female patients have a decreased risk of metastasis. J Invest Dermatol 131:719-726, 2011

18. Koc M, McGregor J, Grecula J, Bauer CJ, Gupta N, Gahbauer RA: Gamma Knife radiosurgery for intracranial metastatic melanoma: an analysis of survival and prognostic factors. $\mathbf{J}$ Neurooncol 71:307-313, 2005

19. Kondziolka D, Patel A, Lunsford LD, Kassam A, Flickinger JC: Stereotactic radiosurgery plus whole brain radiotherapy versus radiotherapy alone for patients with multiple brain metastases. Int J Radiat Oncol Biol Phys 45:427-434, 1999

20. Liew DN, Kano H, Kondziolka D, Mathieu D, Niranjan A, Flickinger JC, et al: Outcome predictors of Gamma Knife surgery for melanoma brain metastases. Clinical article. J Neurosurg 114:769-779, 2011

21. Likhacheva A, Pinnix CC, Parikh NR, Allen PK, McAleer MF, Chiu MS, et al: Predictors of survival in contemporary practice after initial radiosurgery for brain metastases. Int J Radiat Oncol Biol Phys 85:656-661, 2013

22. Mingione V, Oliveira M, Prasad D, Steiner M, Steiner L: Gamma surgery for melanoma metastases in the brain. J Neurosurg 96:544-551, 2002

23. National Cancer Institute: SEER Stat Fact Sheets: Melanoma of the Skin. (http://seer.cancer.gov/statfacts/html/melan.html) [Accessed August 8, 2016]

24. Nieder C, Marienhagen K, Geinitz H, Grosu AL: Can current prognostic scores reliably guide treatment decisions in patients with brain metastases from malignant melanoma? J Cancer Res Ther 7:47-51, 2011

25. Radbill AE, Fiveash JF, Falkenberg ET, Guthrie BL, Young PE, Meleth S, et al: Initial treatment of melanoma brain metastases using Gamma Knife radiosurgery: an evaluation of efficacy and toxicity. Cancer 101:825-833, 2004

26. Robert C, Long GV, Brady B, Dutriaux C, Maio M, Mortier $\mathrm{L}$, et al: Nivolumab in previously untreated melanoma without BRAF mutation. N Engl J Med 372:320-330, 2014 
27. Sahgal A, Aoyama H, Kocher M, Neupane B, Collette S, Tago M, et al: Phase 3 trials of stereotactic radiosurgery with or without whole-brain radiation therapy for 1 to 4 brain metastases: individual patient data meta-analysis. Int J Radiat Oncol Biol Phys 91:710-717, 2015

28. Selek U, Chang EL, Hassenbusch SJ III, Shiu AS, Lang FF, Allen P, et al: Stereotactic radiosurgical treatment in 103 patients for 153 cerebral melanoma metastases. Int J Radiat Oncol Biol Phys 59:1097-1106, 2004

29. Skeie BS, Skeie GO, Enger PO, Ganz JC, Heggdal JI, Ystevik $B$, et al: Gamma Knife surgery in brain melanomas: absence of extracranial metastases and tumor volume strongest indicators of prolonged survival. World Neurosurg 75:684-691, 598-603, 2011

30. Sondak VK, Swetter SM, Berwick MA: Gender disparities in patients with melanoma: breaking the glass ceiling. J Clin Oncol 30:2177-2178, 2012

31. Sperduto PW, Berkey B, Gaspar LE, Mehta M, Curran W: A new prognostic index and comparison to three other indices for patients with brain metastases: an analysis of 1,960 patients in the RTOG database. Int J Radiat Oncol Biol Phys 70:510-514, 2008

32. Yamamoto M, Serizawa T, Shuto T, Akabane A, Higuchi Y, Kawagishi J, et al: Stereotactic radiosurgery for patients with multiple brain metastases (JLGK0901): a multi-institutional prospective observational study. Lancet Oncol 15:387-395, 2014

33. Yu C, Chen JCT, Apuzzo MLJ, O’Day S, Giannotta SL, Weber JS, et al: Metastatic melanoma to the brain: prognostic factors after Gamma Knife radiosurgery. Int J Radiat Oncol Biol Phys 52:1277-1287, 2002

\section{Disclosures}

Eric L. Chang has received honoraria from Brainlab and Elekta for lectures.

\section{Author Contributions}

Conception and design: Bian, Routman, Zada, Trakul, Yu, Chang. Acquisition of data: Bian, Routman, Liu, Yu. Analysis and interpretation of data: Bian, Chang. Drafting the article: Bian, Trakul, Chang. Critically revising the article: Bian, Routman, Liu, Yang, Zada, Trakul, Wong, Yu, Chang. Reviewed submitted version of manuscript: all authors. Approved the final version of the manuscript on behalf of all authors: Bian. Statistical analysis: Yang, Groshen.

\section{Supplemental Information}

Previous Presentations

Portions of this work were presented in an oral plenary session at the 18th Leksell Gamma Knife Society Meeting, Amsterdam, The Netherlands, May 16, 2016.

\section{Correspondence}

Shelly X. Bian, Department of Radiation Oncology, University of Southern California, 1441 Eastlake Ave., NOR G356, Los Angeles, CA 90033. email: shellybian@gmail.com. 